\title{
RESEARCH ON MECHANICAL PROPERTIES OF SINGLE-COMPONENT EPOXY DESIGNED FOR BONDING OF STRUCTURAL JOINTS
}

\author{
Miroslav MÜLLER, Faculty of Engineering, Department of Material Science and Manufacturing Technology, Czech University of \\ Life Sciences, Kamýcká 129, Postal Code: 165 21, Prague, Czech Republic, muller@tf.czu.cz
}

\begin{abstract}
An adhesive bonding technology is among the basic methods of bonding. However, it is limited by several factors, e.g. a treatment of bonded surface. Structural adhesives are chemicals. It follows that there are significant differences in the mechanical properties among particular types.

The aim of the research was to evaluate the mechanical properties of single-component epoxy adhesives used in the transportation industry. The effect of a surface treatment of the steel surface on bond strength was also evaluated. The tested sets were mutually compared using Anova F-test from the point of view of the influence on mechanical properties (the tensile strength of adhesives, the elongation of adhesives, the adhesive bond tensile lap-shear strength, the elongation of the adhesive bond, the impact strength and hardness).

The results confirm the assumption about the different behaviour of one-component epoxy. An important part of the experiment was to evaluate the influence of the surface treatment on the bond strength. From the result of experiments it can be concluded that the adhesive SP492 ( $\mathrm{p}=0.1898)$ and B5103-3 ( $\mathrm{p}=0.4263)$ are resistant to different types of tested treatment of the bonding surface.
\end{abstract}

Keywords: Elongation, Carbon steel, Hardness, Impact strength, Strength

\section{INTRODUCTION}

The production process in various industrial sectors divers, but usually has one common element and that is forming a bond (Müller 2011).

A promising method of creating the bond is the adhesive bonding technology. This technology is often used as a complementary method of joining (Müller 2013; Müller et al. 2013).

According Messler (2004), the bonding is a process of joining materials with the aid of acting chemical agent which is able to keep together these materials via surface attractive forces. Materials that are joined are called adherents, while bonding factor is an adhesive. The forces, which allow the surface attraction, arise from one or more sources, mostly chemical, but some may be mechanical or even electrostatic. These forces give rise to what is called an adhesion, i.e. bonding of different materials together (Messler 2004). The adhesive layer forms the cohesive strength. For the cohesion a summary of forces can be considered that bind the adhesive particles to each other by a valence mutual action and molecular forces of an attraction (Müller, 2013).

The aim of the bonding process is to create a connection that provides maximum strength and quality possible for each combination of adhesive and adherents, usually at minimum costs (Habenicht, 2002). A significant factor affecting the strength of the bond and simultaneously significantly influencing the cost is the surface treatment.

A adequate surface treatment of the connected parts causes an increase of the strength of the adhesive (Uehera, Sakurai 2002; Lunder et al., 2004; Bjorgun et al., 2003; Chen et al., 1997). To obtain a proper and strong bonds, it is essential to start with a clean surface of the adherent because the surface treatment of adherents before bonding is one of the most important operations in the bonding process (Messler 2004). If there is no surface preparation satisfactorily implemented, the bond inevitably and unpredictably fails on the surface of the contact material and the adhesive (Müller, 2011).

The surface treatment is a key factor, not only as regards the initial adhesive strength, but also and especially in terms of its long-term resistance to external influences, which was confirmed by the research (Baker, Chester, 1992).

Careful surface treatment by various mechanical, physical or chemical processes or by combination removes impurities i.e. the "weak boundary layers" and mechanically, physically and chemically determines surfaces of adherents (Prolongo et al., 2006). If the impurities are not removed from the surface or if there area surface layers that are not fixedly connected to the core of adherent, the adhesive is either not able to reach and wet the actual surfaces of adherent or a thin boundary layer is created, thereby reducing the final strength of the bond (Prolongo et al., 2006).

Copyright (C) 2015 The Authors. Published by Aleksandras Stulginskis University. This is an open-access article distributed under the terms of the Creative Commons Attribution License (CC-BY 4.0), which permits unrestricted use, distribution, and reproduction in any medium, provided the original author and source are credited. 
Comyn (1990) in his paper dealt with the theories of the adhesion and methods of adherent surface preparation before bonding. When preparing the surface of metallic materials, particular iron alloys, he recommends the use of mechanical operations. The use of chemical cleaning is appropriate to reduce, if necessary, only for degreasing processes, which are designed to remove oil, grease, etc.

\section{METHODOLOGY}

The aim of the research was to evaluate the mechanical properties of single-component epoxy used in the transportation industry. Structural adhesives are used one of methods for bonding of coach - works of tractors and other agricultural electricity machines. Other areas are machines for processing a soil and for sowing. Using the adhesive bonding technology increases a rigidity of an adhesive bonded construction. The effect of the surface treatment of the steel surface on bond strength was also evaluated.

As adhesives one component, epoxy based adhesives especially developed for the body shop were used. The adhesives are used in the car to increase the operation durability and the body stiffness. As a matter of fact following adhesives which were hardened at increased temperature according to requirements of the producer were used:

- $\quad$ Sika Power 492 (marked SP492),

- Betamate 1496F (marked B1496F),

- Betamate 1440G (marked B1440G),

- $\quad$ Betamate 5103-3 (marked B5103-3).

Assessed mechanical properties of adhesive were: - tensile strength, elongation, impact strength and hardness.

Tensile test: The test specimens for the tensile properties determination according to the standard CSN EN ISO 527-1 (Plastics - Determination of tensile properties - Part 1: General principles) were prepared according to the standard CSN EN ISO 3167 (Plastics - Multipurpose test specimens). By the destructive testing the tensile strength and the elongation were determined.

The moulds for casting of the test specimens were made from the material Lukapren $\mathrm{N}$ using prepared models. The shape and sizes of moulds meet the corresponding standards. The mould consisted of two parts in order to reach an even surface on both sides of the test specimens.

Adhesive bonds: The basis of adhesive bonds laboratory testing was the determination of the tensile lap-shear strength of rigid-to-rigid bonded assemblies according to the standard CSN EN 1465 (Equivalent is BS 1465).

Specimens of all the tested materials were obtained identically - cutting from the semi-products in the hydraulic guillotine sheet metal machine. Laboratory tests of the adhesive bonds were performed using the standard test specimens made according to the standard CSN EN 1465 (dimensions $100 \pm 0.25 \times 25 \pm 0.25 \times 1.6 \pm 0.1 \mathrm{~mm}$ and lapped length of $12.5 \pm 0.25 \mathrm{~mm}$ ) from the constructional plain carbon steel S235J0. These surface treatments were tested:

- Without mechanical and chemical treatment (marked $\mathrm{A})$,

- Mechanical treatment - grit blasted F $80\left(\mathrm{Al}_{2} \mathrm{O}_{3}\right)$ / chemical treatment - degreased with Acetone (marked B),

- Without mechanical treatment / chemical treatment - degreased with Acetone (marked C).

The surface preparation is important and should guarantee good strength on the boundary adherent/adhesive/adherent (Novák, 2011; Hricová, 2014). An even thickness of the adhesive layer was reached by a constant pressure $0.5 \mathrm{MPa}$. The lapping was according to the standard $12.5 \pm 0.25 \mathrm{~mm}$.

The failure type according to ISO 10365 was determined at the adhesives bonds. The tensile strength and the elongation test (the adhesive bond, the cast of the test specimens) were performed using the universal tensile strength testing machine LABTest 5.50ST (a sensing unit AST type KAF $50 \mathrm{kN}$, an evaluating software Test\&Motion). A speed of the deformation corresponded to $2 \mathrm{~mm} \cdot \mathrm{min}^{-1}$.

Impact strength: The impact strength was set in an apparatus Dynstat determined for the testing of plastics. The test specimen preparation and impact tests were performed according to the standard CSN 640611 (Determination of the impact resistance of rigid plastics by means of Dynstat apparatus). By the destructive testing the impact strength was determined.

Hardness SHORE D: Material hardness was measured by Shore D i.e. by pressing the tip of the instrument durometer Shito HT. The hardness SHORE D was measured according to the standard CSN EN ISO 868. Test specimens were $5 \mathrm{~mm}$ high.

For the correct evaluation it is also important to determine the determination index $\mathrm{R}^{2}$. It is the problem of the correlation analysis. The values of the determination index can be from 0 to 1 . So far as $\mathrm{R}^{2}$ equals to 1 , there is a perfect correlation in this sample (so there is no difference between a calculation and real values).

The tested sets were mutually compared using F-test from the point of view of the influence on mechanical properties (the tensile strength of adhesives, the elongation of adhesives, the adhesive bond tensile lap-shear strength, the elongation of the adhesive bond, the impact strength and hardness).

The zero hypothesis $\mathrm{H}_{0}$ presents the state when there is no statistically significant difference $(p>0.05)$ among tested sets of data from their mean values point of view.

\section{RESULTS AND DISCUSSION}

The tensile strength in all four evaluated adhesives ranged from 38 to $42 \mathrm{MPa}$ (Figure 1). The highest tensile strength was reached by the adhesive B1496F (41.99 $\pm 1.48 \mathrm{MPa})$. Manufacturer's declared values of the tensile strength have been verified. The elongation was significantly different for each adhesive. The lowest values were measured for the adhesive B5103-3 (4.62 $\pm 0.30 \%)$. The highest value was for the adhesive B1496F (12.81 $\pm 0.40 \%)$. 


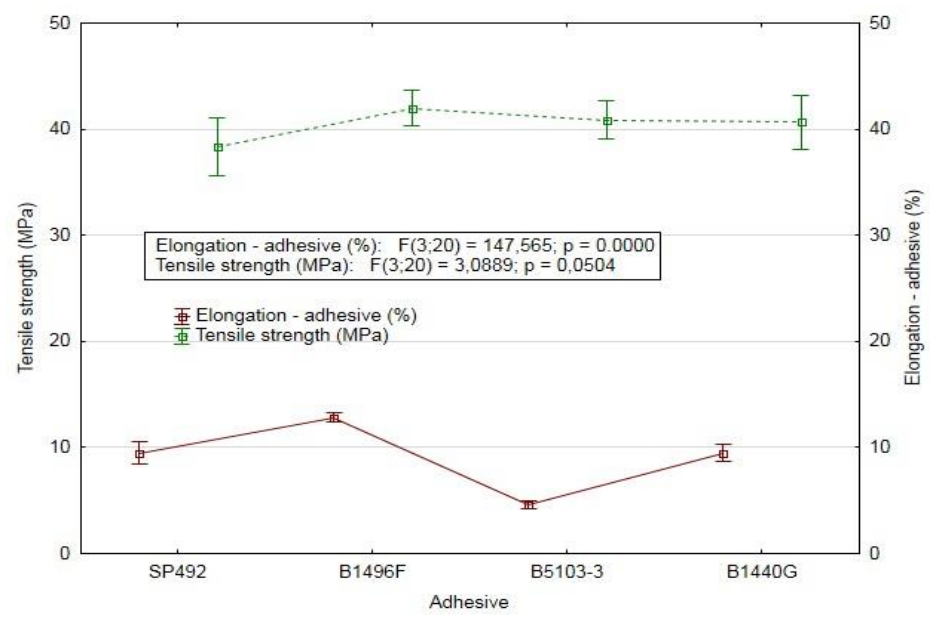

Figure 1. Tensile strength and Elongation of adhesives

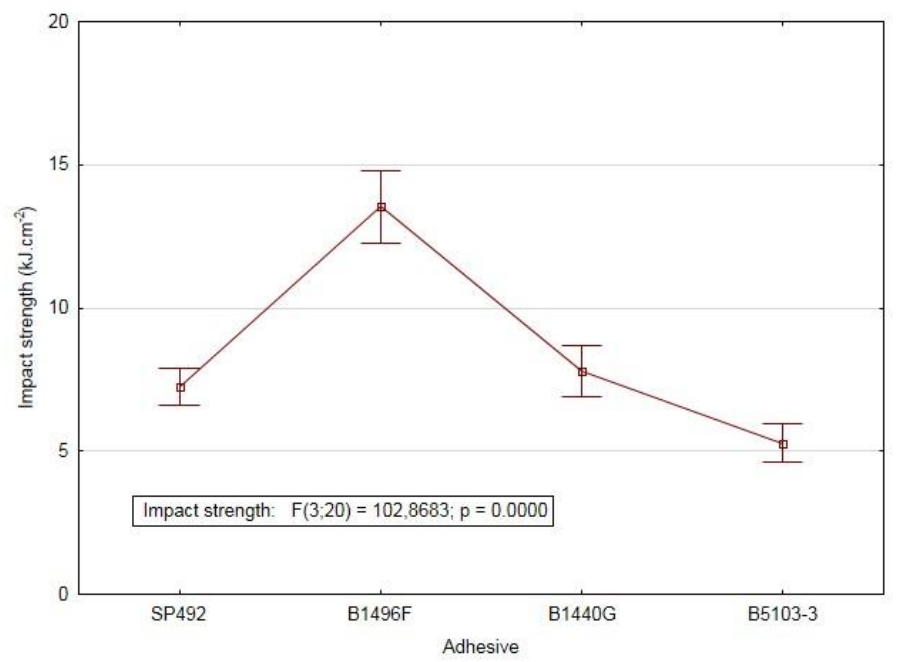

Figure 2. Impact strength of adhesives

Figure 2 shows the results of the impact strength. The highest impact strength was reached by the adhesive B $1496 \mathrm{~F}\left(13.55 \pm 1.1 \mathrm{~kJ} \cdot \mathrm{m}^{-2}\right)$.

The other three adhesives reached similar results. Adhesives SP492, B1440G B5103-3 ranged from 5.28 to $7.80 \mathrm{~kJ}^{-2} \mathrm{~m}^{-2}$. When comparing the results of the hardness Shore D and the impact strength, it is evident that the adhesive with smaller hardness achieved higher values of the impact strength.

The hardness Shore D tested on cast specimens is shown in Figure 3. The highest hardness after curing was achieved by the adhesive SP492 (83.94 \pm 1.28$)$, the lowest hardness was observed at the adhesive B1496F $(76.15 \pm 2.82)$.

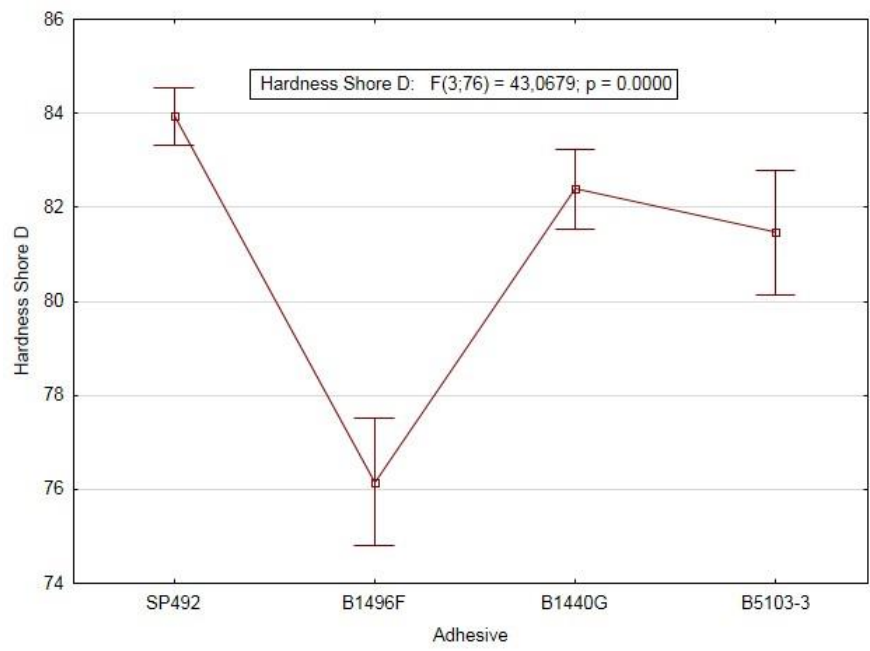

Figure 3. Hardness Shore D of adhesives 
Using the profilograph Surftest 301 the following values were determined: Adhesive bonds of series A and $\mathrm{C}-\mathrm{Ra} 0.75 \pm 0.13 \mu \mathrm{m}, \mathrm{Rz} 3.84 \pm 0.72 \mu \mathrm{m}$, adhesive bonds of series B - Ra $1.64 \pm 0.21 \mu \mathrm{m}, \mathrm{Rz} 9.14 \pm 1.22 \mu \mathrm{m}$. The thickness of the adhesive layer was $0.36 \pm 0.02 \mathrm{~mm}$.

The loading speed of the adhesive bonds was determined such that the destruction of the bond was in accordance with the standard DIN EN 1465 at an interval of $65 \pm 20 \mathrm{~s}$ (Figure 4). From the results of similar single-component adhesives, it is clear that these are speeds below $10 \mathrm{~mm} \cdot \mathrm{min}^{-1}$ within (Müller, Cidlina, 2015). The research the interval from 1 to $6 \mathrm{~mm} \cdot \mathrm{min}^{-1}$ was thus evaluated. The results are shown in Fig. 4 . In the figure there is also indicated the minimum and maximum time for a failure of the adhesive bond set by standard. Adhesive bonds were tested by a speed 2 mm.min ${ }^{-1}$.

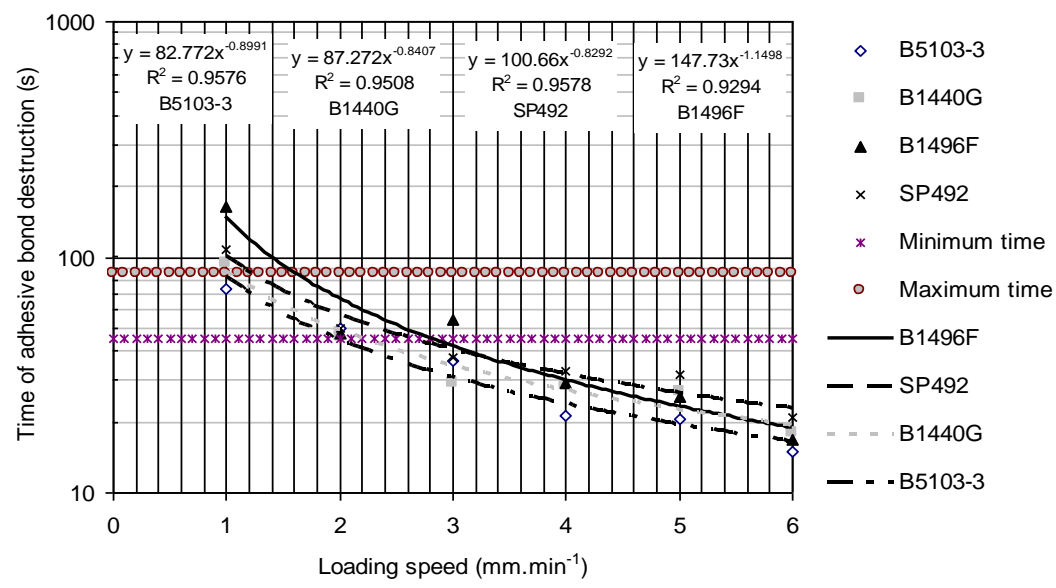

Figure 4. Influence of loading speed on time of adhesive bond destruction (Equations of functions: $y$ - time of adhesive bond destruction, $\mathrm{x}$ - loading speed)

The significance of the surface treatment of the adhesive bond has been demonstrated in many studies (Müller, Valášek, 2013; Valášek, 2014; Valášek, 2014; Müller, 2014). A development of adhesives, however, aims to minimize the factors affecting the preparation of the bonded surface. The results of the mechanical properties of adhesive bonds are seen in Figures 5 and 6. From the experimental results it is obvious that the combination of mechanical and chemical treatment provides the highest adhesive bond tensile lap-shear strength (variant B). When the bond without mechanical and chemical treatment was created, its strength decreased and ranged from 2.7 to $19.1 \%$ compared by the standard variant B. When the bond was treated only with chemical cleaning of the surface (without mechanical surface treatment), the loss of strength was in the interval ranged from 0.9 to $20.2 \%$ the standard variant B.

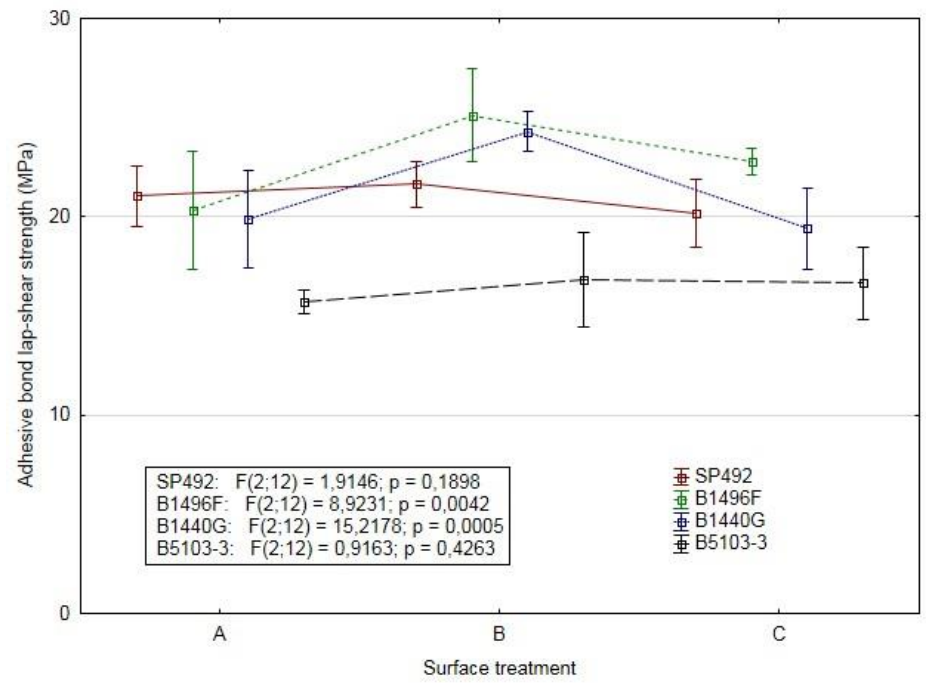

Figure 5. Adhesive bond tensile lap-shear strength

A similar trend also showed the elongation of the adhesive bond. Optimum properties were achieved by the type B bonds (Mechanical treatment - grit blasted F 80 (Al2O3) / chemical treatment - degreased with acetone).

When evaluating the failure area, the adhesive-cohesive type of the failure of the bond was determined at the bond A and C (Figure 7). For the surface treatment B the failure area was of a cohesive type (Figure 7). The influence of the surface treatment on the change of the failure area was proved. Due to the deformation (bending moment) of the bonded material, the breach of the bond occurred at the boundary of the adhesive and the bonded material. Similar results were reached when 1.5 and $3 \mathrm{~mm}$ thick bonded materials were compared (Valášek, Müller, 2015). 


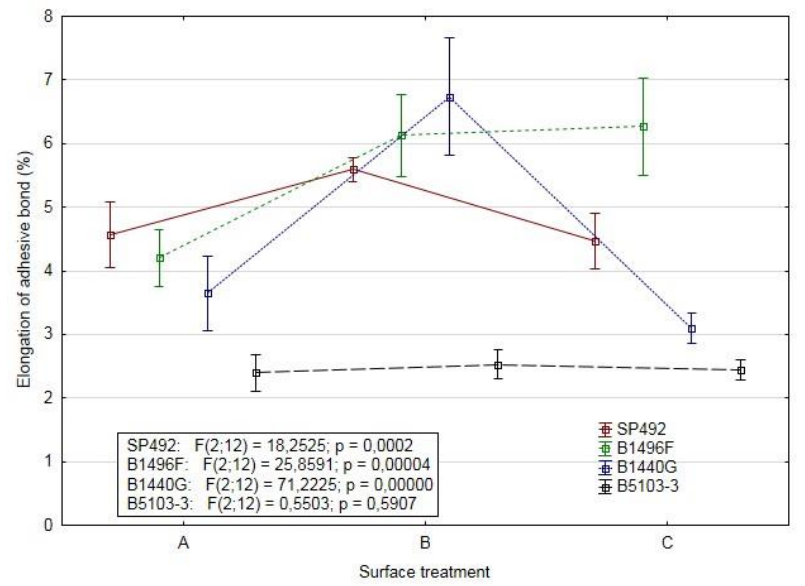

Figure 6. Elongation of adhesive bond.
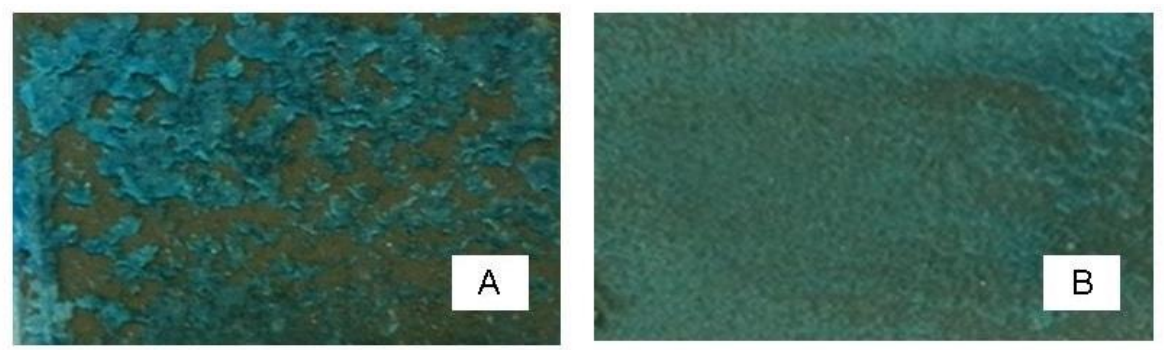

Figure 7. Failure area - A: Adhesive - Cohesive type of breach of bond, B: Cohesive type of failure of bond

Structural adhesives based on epoxy intended for structural bonding in the automotive industry exhibit increased mechanical properties. For example, the shear strength is higher than at commonly used two-component epoxy resins, whose values of the shear strength depending on the type range from 2 to $18 \mathrm{MPa}$ (Müller et al., 2014; Cidlina et al., 2014).

\section{CONCLUSION}

From the results obtained in this experiment it is possible to establish the following conclusions:

- The tensile strength of one component epoxy adhesive is 38 to $42 \mathrm{MPa}$. Based on the statistical test, the hypothesis $\mathrm{H}_{0}$ was confirmed, i.e. there is no difference in the significance level of 0.05 among the tested adhesives. For the elongation of adhesives the hypothesis H0 was not confirmed, i.e. there is the difference between individual tested adhesives.

- Different behaviour of tested adhesives occurred at the impact strength. According to the statistical survey, there is the difference between the tested adhesives.

- Different behaviour of tested adhesives occurred at the hardness Shore D. According to a statistical survey, there is the difference between the tested adhesives.

- An important part is the evaluation of the impact of the surface treatment on the bond strength. From the obtained results it can be concluded that the adhesive SP492 ( $p=0.1898)$ and B5103-3 ( $p=4263)$ confirmed the hypothesis $\mathrm{H}_{0}$. It follows that there is no difference in the treatment of the bonding surface A, B and C. For adhesives B1496F $(p=0.0042)$ and B1440G $(p=0.0005)$ the influence of the treatment of the bonding surface was statistically shown at a significance level of 0.05 . At the elongation of adhesives SP492, B1496F and B1440G the influence of bonding surface treatment was statistically proved.

Acknowledgement. This paper has been done when solving IGA 31140/1312/313106.

\section{REFERENCES}

1. Baker, A. A., Chester, R. J. 1992. Minimum surface treatments for adhesively bonded repairs. International Journal of Adhesion \& Adhesives, Vol. 12, No. 2, pp. 73-78. http://dx.doi.org/10.1016/0143-7496(92)90026-R

2. Bjorgum, A., Lapique, F., Walmsley, J., Redford, K. 2003. Anodising as pre-treatment for structural bonding. International Journal of Adhesion \& Adhesives, Vol. 23, No. 5, pp. 401-412. http://dx.doi.org/10.1016/S0143-7496(03)00071-X

3. Comin, J. (1990). Surface treatment and analysis for adhesive bonding. International Journal of Adhesion \& Adhesives, Vol. 10, No. 3, pp. 161-165. http://dx.doi.org/10.1016/0143-7496(90)90099-J

4. Cidlina, J., Müller, M., Valášek, P. 2014. Evaluation of adhesive bond strength depending on degradation type and time. Manufacturing Technology, Vol. 14, pp. 8-12. 
5. CSN EN ISO 527-1 (2012). Plastics - Determination of tensile properties - Part 1: General principles. Czech Standard Institution. (in Czech)

6. CSN EN ISO 3167 (2004). Plastics - Multipurpose test specimens. Czech Standard Institution. (in Czech)

7. CSN EN 1465 (2009). Adhesives - Determination of tensile lap-shear strength of bonded assemblies. Czech Standard Institution. (in Czech)

8. CSN 640611 (1993). Determination of the impact resistance of rigid plastics by means of Dynstat apparatus. Czech Standard Institution. (in Czech).

9. CSN EN ISO 868 (2003). Plastics and ebonite - Determination of indentation hardness by means of a durometer (Shore hardness). Czech Standard Institution. (in Czech)

10. Habenicht, G. 2002. Kleben: Gundlagen, Technologien, Anwendung. Berlin: Springer 2002. 921 pp. http://dx.doi.org/10.1007/9783-662-08085-6

11. Hricova, J. 2014. Environmentally conscious manufacturing: the effect of metalworking fluid in high speed machining. Key engineering materials, Vol. 581, pp. 89-94. http://dx.doi.org/10.4028/www.scientific.net/KEM.581.89

12. Chen, S., Ono, S., Teii, S., Yoshino, T. 1997. Improvement of the adhesion of the resin to the metal surface by using plasma jet. Surface and Coating Technology, Vol. 97, No. 1-3, pp. 378-384. http://dx.doi.org/10.1016/S0257-8972(97)00242-9

13. Lunder, O., Lapique, F., Johnsen, B., Nisancioglu, K. 2004. Effect of pre-treatment on the durability of epoxy-bonded AA6060 aluminium joints. International Journal of Adhesion \& Adhesives, Vol. 24, No. 2, pp. $107-117$. http://dx.doi.org/10.1016/j.ijadhadh.2003.07.002

14. Messler, R., W. 2004. Joining of materials and structures from pragmatic process to enabling technology. Burlington: Elsevier, 790 pp.

15. Müller, M. 2011. Influence of surface integrity on bonding process. Research in Agricultural Engineering, Vol. 57, No. 4, pp. 153-162.

16. Müller, M. 2013. Research of renovation possibility of machine tools damage by adhesive bonding technology. Manufacturing Technology, Vol. 13, No. 4, pp. 504-509.

17. Müller, M. 2014. Setting of causes of adhesive bonds destruction by means of optical analysis. Manufacturing Technology, Vol. 14, pp. 371-375.

18. Müller, M., Cidlina, J. 2015. Research of loading of structural bonds created with one-component epoxy adhesives. Manufacturing technology, Vol. 15, pp. 183-188.

19. Müller, M., Herák, D., Valášek, P. 2013. Degradation limits of bonding technology depending on destinations on destinations Europe, Indonesia. Tehnicki Vjesnik-Technical Gazette, Vol. 20, No. 4, pp. 571-575.

20. Müller, M., Ružbarský, J., Valášek, P. 2014. Degradation process in area of connecting metal sheets by adhesive. Applied Mechanics and Materials, Vol. 616, pp. 52-60. http://dx.doi.org/10.4028/www.scientific.net/AMM.616.52

21. Müller, M., Valášek, P. 2013. Comparison of variables influence on adhesive bonds strength calculations. Manufacturing Technology, Vol. 13, pp. 205-210.

22. Novák, M. 2011. Surface duality hardened steels after grinding. Manufacturing technology, Vol. 11, pp. 55-59.

23. Prolongo, S. G., Gilberto del Rosario, Ureňa, A. 2006. Comparative study on the adhesive properties of different epoxy resins. International Journal of Adhesion \& Adhesives, Vol. 26, No. 3, pp. 125-132. http://dx.doi.org/10.1016/j.ijadhadh.2005.02.004

24. Uehara, K., Sakurai, M. 2002. Bonding strength of adhesives and surface roughness of joined parts. Journal of Materials Processing Technology, Vol. 127, No. 2, pp. 178-181. http://dx.doi.org/10.1016/S0924-0136(02)00122-X

25. Valášek, P. 2014. Mechanical Properties of Epoxy Resins Filled with Waste Rubber Powder. Manufacturing technology, Vol. 14, pp. 632-637.

26. Valášek, P. 2014. Long-term degradation of composites exposed to liquid environments in agriculture. Scientia Agriculturae Bohemica, Vol. 45, No. pp. 187-192.

27. Valášek, P., Müller, M. 2015. Properties of adhesives used for connecting in automotive used for connecting in automotive industry. Acta Universitatis agriculrurae et Silviculturae Mendelianae Brunensis, Vol. 63. pp. 463-470. 